\title{
Local habitat patch pattern of the Siberian flying squirrel in a managed boreal forest landscape
}

\author{
Eija Hurme, Pasi Reunanen, Mikko Mönkkönen, Ari Nikula, Vesa Nivala and Jari Oksanen \\ E. Hurme (Eija. Hurme@oulu.fi), P. Reunanen and J. Oksanen, Dept of Biology, P.O. Box 3000, FI-90014 Univ. of Oulu, Finland. \\ - M. Mönkkönen, Dept of Biological and Environmental Science, P.O. Box 35, FI-40014 Univ. of Jyväskylä, Finland. - A. Nikula \\ and V. Nivala, Finnish Forest Research Inst., Rovaniemi Research Station, P.O. Box 16, FI-96301 Rovaniemi, Finland.
}

\begin{abstract}
We examined how the structure of a boreal forest landscape is related to the occurrence of the Siberian flying squirrel Pteromys volans in northern Finland. The flying squirrel inhabits mature spruce-dominated (Picea abies) mixed forests and is categorised as vulnerable species due to habitat loss and change. We classified a landscape of $374.5 \mathrm{~km}^{2}$ into potential habitat patches, potential dispersal areas, and areas incapable of being inhabited using national forest inventory data, and surveyed all 136 potential habitat patches for the presence of the species. Different landscape variables were defined, and also connections by the shortest distances to neighbouring habitat patches along both straight lines and least-cost distances based on specific movement costs were measured. Occupied patches were larger in size, contained more deciduous trees for food and nesting cavities, and were in closer proximity to the nearest occupied patches. Occupied patches were mainly located below 300 $\mathrm{m}$ a.s.l. The occurrence of flying squirrels was correctly predicted for $88 \%$ of the habitat patches using landscape variables. This modelling result proved to be rather general. In addition, the configuration of occupied patches was mainly clustered across the landscape, and distant occupied patches seemed to be linked to other patches via forested connections. We suggest that maintaining a clustered arrangement of good quality habitat patches and regenerating new potential habitat as well as dispersal areas between the habitat patches seem to be appropriate goals for long-term forest management planning to sustain populations of the flying squirrel in the landscape.
\end{abstract}

Conservation biology calls for the long-term maintenance of necessary patterns and processes in ecological systems (Soule 1985). The emphasis is on the availability of habitats for a species, survival and reproduction in a landscape. All landscapes are heterogeneous habitat mosaics in space and time (Wiens 1995). Landscape characteristics may be broadly defined by the amount of each landscape element (composition) such as patches of suitable habitat, the spatial location of the elements (configuration), and also by the functional relationships between the different elements in a landscape, such as connectivity, that reflect how individuals move between habitat patches (Merriam 1984, Taylor et al. 1993). Different species perceive the landscape differently reflecting their ability to reach suitable habitat patches (Lidicker 1999). Habitat availability is a matter of great importance since a change of landscape characteristics through habitat loss, degrada- tion, and fragmentation is the main global threat to species persistence (Saunders et al. 1991, Fahrig 1997, 2002, Bender et al. 1998, Harrison and Bruna 1999).

In recent decades the number of mature forests in Fennoscandia has decreased, and forest structure has changed (Esseen et al. 1997, Östlund et al. 1997). The area of monoculture forests has increased, and variation in tree species, size, and age composition within forests has narrowed (Esseen et al. 1997). As a result, in Finland many forest-associated species have faced considerable changes in habitat availability, followed by population decline (Rassi et al. 2001). The ability of species to reach other habitats also depends on both the structural characteristics of a landscape and species behaviour, which together define habitat connectivity in a landscape (Merriam 1984, Tischendorf and Fahrig 2000). The quality of the matrix, the area surrounding the habitat patches, may thus affect the actual isolation 
of habitat patches (Taylor et al. 1993, Åberg et al. 1995).

Therefore, the pattern of habitat occupancy for a species may provide evidence of habitat connectivity (Merriam 1995).

We focus on the habitat responses of the Siberian flying squirrel Pteromys volans, an arboreal rodent in Eurasian taiga forests. Flying squirrels prefer sheltered, spruce-dominated (Picea abies) mixed forests with a distinctive deciduous tree component for food, and large aspens (Populus tremula) for nesting cavity trees (Hanski 1998, Reunanen et al. 2002a). In northern Finland, flying squirrels prefer habitats that are situated within larger forest tracts or linked with forested connections to other habitat patches (Mönkkönen et al. 1997, Reunanen et al. 2000, 2002b). The flying squirrel is categorised as a vulnerable species in Finland according to IUCN criteria (Rassi et al. 2001) due to the recent population decline, most likely caused by habitat loss and degradation. Therefore, the breeding sites of the flying squirrel are protected (Rassi et al. 2001, Anon. 2003). However, present knowledge at the scale of forest patches is insufficient to make practical conclusions concerning how to manage forests to maintain flying squirrel populations in these landscapes.

The objective of this study was to examine which landscape characteristics explain and predict the occurrence of the Siberian flying squirrel on a local scale in a boreal forest landscape in northern Finland. We used classified satellite images to categorise our study area into 3 habitat classes for the flying squirrel: potential habitat, potential dispersal areas, and areas incapable of being inhabited. In addition, we surveyed all patches of potential habitat for species occurrence, and built and evaluated a predictive model using landscape variables to estimate the probability of the occurrence of the flying squirrel in habitat patches. Finally, we discuss the utility of our landscape categorisation and occupancy models for landscape planning and species conservation.

\section{Materials and methods}

\section{Study area}

Our study area, $374.5 \mathrm{~km}^{2}$ in size, is situated in northern Finland $\left(65^{\circ} 30^{\prime} \mathrm{N}, 28^{\circ} 15^{\prime} \mathrm{E}\right)$ and lies within the northern boreal vegetation zone (Ahti et al. 1968). The toporgraphy of the land within the study area ranges from 180 to $380 \mathrm{~m}$ a.s.l. forming a diverse landscape of forested hills. In addition, open fens, pine bogs, and a few small lakes characterize the study area. Coniferous forests cover ca $70 \%$ of the study area, and are dominated by Scotch pine Pinus sylvestris and spruce mixed with deciduous trees such as birch Betula spp., aspen, and alder Alnus incana. Almost two-thirds of the forest land is pine dominated and $<60 \mathrm{yr}$ of age. One quarter of the forests are $>100 \mathrm{yr}$ old and are mostly spruce dominated. Forests of $60-100$ yr old cover only a few percentages of the study area.

\section{Land use and forest data}

We used multi-source national forest inventory (MSNFI) data (Tomppo 1993) for habitat type classification. In compiling MS-NFI data, field study plot information is integrated with digital maps of peat lands and non-forest land like roads, agricultural fields, and inhabited areas to derive estimates of forest parameters from Landsat TM 5 satellite image (Tomppo 1993). The method produces estimates of forest structure variables, such as tree species and their volumes per hectare, for $25 \times 25 \mathrm{~m}$ pixels. Estimates are produced separately for Scots pine, spruce, and birch (B. pendula and B. pubescens not separated) but estimates of other deciduous trees are presented as a combined estimate. The resolution of the image is too coarse to present information about individual deciduous trees or small tree groups (Reunanen et al. 2002a). Since the original satellite images for our study area were recorded in 1993, they were updated with data from regeneration areas after 1993 (from Metsähallitus, an organisation governing state-owned lands and waters). Misclassifications observed in the forests during field-work were also corrected. Other than harvesting, no major changes affecting habitat classification existed. Algorithms tailored for this study and based on spatial analysis tools in ArcInfo 8 (McCoy and Johnston 2001) were used to calculate landscape metrics.

\section{Habitat classification and field work}

We classified the landscape as potential habitat, potential dispersal areas, and areas incapable of being inhabited (Fig. 1). Males use home ranges averaging 60 ha in size, whereas females inhabit home ranges averaging 8 ha (Hanski et al. 2000). Flying squirrels move moderately well in forested landscapes by gliding from tree to tree (Selonen and Hanski 2004), and their home ranges consist of separate core areas, which are rich in deciduous trees and where the individuals spend a majority of their time (Hanski 1998). Females especially prefer spruce-dominated forests with a deciduous tree component for breeding (Hanski 1998, Hanski et al. 2000). Therefore, for potential habitat we targeted core pixels, which indicated mature sprucedominated forest with deciduous trees in the mixture characterizing the preferred habitat for females. Criteria for selecting these core pixels were 1) the volume of spruce was $>80 \%$ of the total timber volume, or 


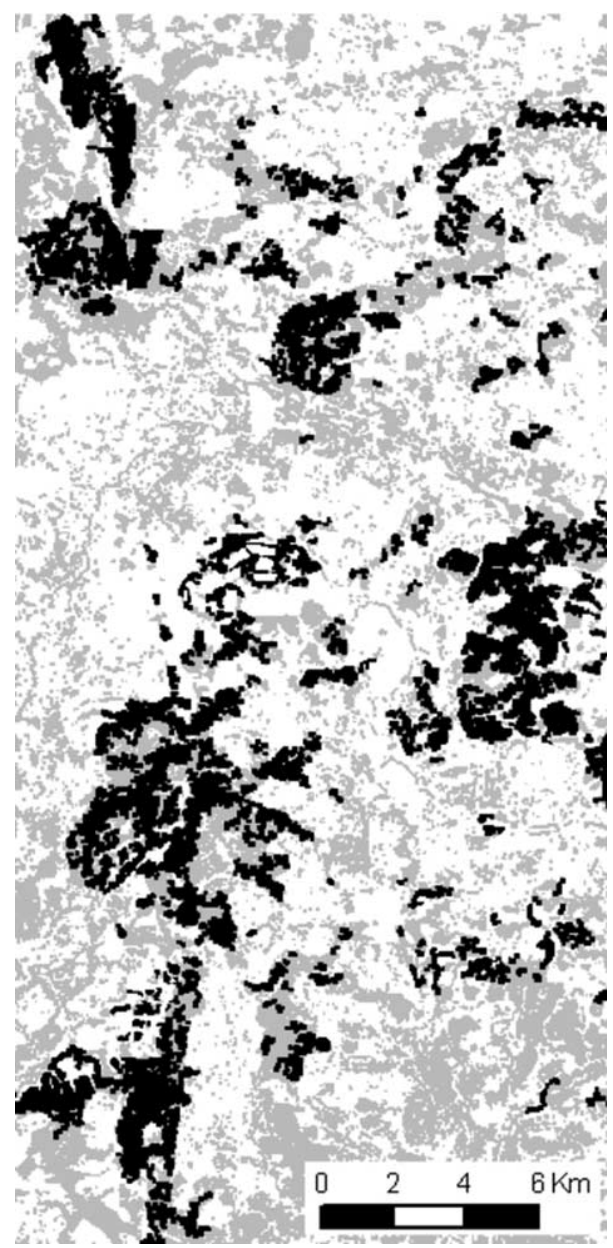

Fig. 1. Landscape composition of the study area; black corresponds to patches of potential habitat, grey to potential dispersal areas, and white to areas incapable to being inhabited.

volumes of spruce and deciduous trees together comprised $>80 \%$ of the total timber volume, and 2) the total timber volume was set to $100 \mathrm{~m}^{3} \mathrm{ha}^{-1}$. These criteria are the same as those used in earlier studies on the flying squirrel in this region (Reunanen et al. 2002b, 2004).

We formed patches of potential habitat, hereafter referred to as habitat patches, by adding a 50-m buffer to the core pixels. Thus, the core pixels were united as a habitat patch if they were situated within $100 \mathrm{~m}$ of each other (i.e. their buffers overlapped or adjoined). This procedure was likely to reflect habitat patches based on the ecology of the species. We did not specify the properties of the buffer pixels (even open gaps up to $100 \mathrm{~m}$ wide could be included within a habitat patch) since flying squirrels easily cross forest gaps of $20-70 \mathrm{~m}$ in one glide (Selonen and Hanski 2004). Typically, open areas inside a habitat patch were very small.
However, habitat patches $<3.5$ ha (area of core pixels $\leq 1 \mathrm{ha}$ ) were still excluded from analysis because separate forests smaller than this size are too small to support a breeding female (Hanski et al. 2000, Selonen et al. 2001).

The purpose of potential dispersal area in the landscape was to define forest approximately $\geq 10 \mathrm{~m}$ high. Flying squirrels seem to prefer closed canopy forests for moving (Selonen and Hanski 2003, 2004), and forests of $\geq 10 \mathrm{~m}$ seem to permit easy movement (Reunanen et al. 2000). For the dispersal pixels, the criterion of total timber volume was set to be $\geq 75 \mathrm{~m}^{3}$ $\mathrm{ha}^{-1}$ irrespective of tree species, which in our study area represents $\geq 10 \mathrm{~m}$ high (Gustavsen 1980), middleaged mature forests (Tomppo et al. 1998). Dispersal pixels were buffered by $25 \mathrm{~m}$, and were united as potential dispersal area if buffers overlapped or adjoined. Thus, the maximum distance between two dispersal pixels within the potential dispersal area was $50 \mathrm{~m}$, a distance easily crossed by gliding. All other landscape elements such as a few lakes, open bogs, fields, clear cut areas, sapling stands, and young forests were classified as areas incapable of being inhabited.

During the times of our landscape classification and field surveys (year 2000), a majority of the non-forest area on mineral soils in our landscape classification were sapling stands either $20-25 \mathrm{yr}$ old (ca 5-8 $\mathrm{m}$ high at these latitudes) or 5-10 yr old (ca 2-5 m). Our potential dispersal area, middle-aged and mature forests, thus reflects forests well suited for dispersal, especially for longer distances at the landscape scale. However, younger forests can also be used for moving and short distances of relatively open areas can be crossed (Selonen and Hanski 2003). Therefore, possible use of parts of the areas incapable of being inhabited by flying squirrels cannot be totally excluded. However, a rather robust landscape classification was relevant in our approach at a larger landscape scale.

The classification and buffering procedure resulted in 136 habitat patches in the study area. We surveyed all habitat patches to determine the presence or absence of flying squirrels. Presence was based on the finding of the faeces of the species, the distinctive yellowish pellets the size of rice grains, which typically accumulate around the bases of large spruce and aspens indicating the most frequently used and occupied areas within the forest (Reunanen et al. 2002b). The pellets accumulate during late winter and spring, and remain as late as the early summer when they can still be found relatively easily (before decomposing). As such, the pellets indicate the use of a forest at least during the last few months. Every patch was visited once in June 2000. After the pellets were found, a habitat patch was assigned as occupied. To confirm the absence of the 
species the whole habitat patch was surveyed thoroughly without a time limit.

\section{Landscape metrics}

We measured 15 variables to describe different characteristics of the landscape: the habitat patches, landscape matrix, and connections between neighbouring habitat patches. The variables were kept as simple as possible. The attributes primarily relating to habitat patches were the total area of a habitat patch (Patch area; ha), the total area of core pixels (Core-area; ha), and the proportion of core pixels in a habitat patch (Core-prop). Habitat variation within a boreal forest often indicates the presence of deciduous trees that are important resources for the flying squirrel, so we also calculated the number of separate groups of core pixels within a habitat patch (Core-group). The elevation of the habitat patch was measured using the minimum altitude of a habitat patch. (Aslmin; $\mathrm{m}$ a.s.l.) and by defining the size of the habitat patch area that was situated $<300 \mathrm{~m}$ a.s.l. (Lowarea; ha). We also measured the tree volume $\left(\mathrm{m}^{3} \mathrm{ha}^{-1}\right)$ of spruce (Spruce) and deciduous trees (Deciduous) within a habitat patch.

We described the surrounding matrix of a habitat patch by calculating the proportions of the three habitat classes around it within a distance of $500 \mathrm{~m}$ measured from the borders of a habitat patch. The proportion of potential habitat ( $\mathrm{PH} 500$; patches), potential dispersal area (DA500), and areas incapable of being inhabited (IA500) within a $500 \mathrm{~m}$ radius around a habitat patch equaled $100 \%$. The $500 \mathrm{~m}$ distance was chosen for three reasons: 1) it reflects the surrounding area that most juveniles cross when dispersing from their natal forest (Selonen and Hanski 2004), 2) it roughly covers the nightly moving distances of adult flying squirrels within their home ranges (Hanski et al. 2000), and 3) in practise it results in largely non-overlapping patch surroundings in the study landscape and therefore avoids statistical interdependency of habitat patches.

The spatial context of a habitat patch relative to the distances to the nearest neighbouring habitat patches were estimated in two ways. The proximity of an occupied site may increase the probability of the occupancy of the neighbouring site due to, for example, dispersal. So we also measured the distances to the nearest occupied patches. We measured a straight edgeto-edge-distance to the nearest neighbour patch without information on its occupancy status (SDnnp; m), and separately to the nearest occupied patch (SDnop; m). In forestry planning the occupancy status of the neighbouring forests is rarely known, so both of these distances were measured to estimate if the knowledge of the neighbour's occupancy provides relevant addi- tional information for explaining the occupancy of a focal habitat patch.

Straight edge-to-edge distance is often used for simplicity. However, this is not necessarily the most obvious route for mammals, which may choose their route according to its safety: flying squirrels have been found to choose forested routes if possible (Selonen and Hanski 2004). We calculated least-cost distances between habitat patches based on cost-per-unit distance and accumulative costs (for the method, see e.g. McCoy and Johnston 2001, Ray et al. 2002). At first, the calculation began with defining a cost surface where each pixel in the study area was assigned a cost for traversing one meter within that landscape element (Nikula et al. 2001). The maximum cost in each landscape element was calculated by dividing maximum theoretical dispersal distance in metres by cell size, and multiplying the result by cell size $\times$ cost per unit (for a diagonal to cell distance $\sqrt{ } 2 \times$ cell size $\times$ cost per unit). The maximum dispersal distances were: potential habitat $=$ no maximum; potential dispersal area $=$ $5000 \mathrm{~m}$; other forests and saplings $\left(25-75 \mathrm{~m}^{3}\right.$ $\left.\mathrm{ha}^{-1}\right)=500 \mathrm{~m}$; fields and other open area $=200 \mathrm{~m}$; and water $=50 \mathrm{~m}$. Flying squirrels avoid totally open areas such as water and fields (Hanski et al. 2000, Selonen and 2003, 2004), where the moving distances are limited by gliding abilities. A majority of young flying squirrels disperse ca $3 \mathrm{~km}$ during their first autumn (Selonen and Hanski 2004), which justifies the maximum distance of $5 \mathrm{~km}$ via our potential dispersal areas.

Second, the algorithm calculates a least-accumulative cost distance along the cost surface to the habitat patches of every pixel outside the habitat patches. Pixels outside the maximum cost (maximum dispersal distance) are regarded as non-reachable in future calculations. Third, the least-accumulative cost is calculated individually for each habitat patch of every pixel within the study area. The "optimal" least-cost distance is thus a combination of the use of different landscape elements, but most likely follows the forested routes. Finally, the algorithm finds the least-cost path between habitat patches and calculates the geographic distances along least-cost paths in two ways: a distance to the nearest neighbour patch irrespective of its occupancy status (CDnnp) and to the nearest occupied patch (CDnop).

\section{Statistical analyses}

We compared characteristics of occupied and unoccupied habitat patches using raw data. Because of multicollinearity between the variables (Mac Nally 2000), we used principal component analysis (PCA) with varimax rotation to compress the information of 
original variables into new uncorrelated variables (eigenvalue $>1$ ) for further analyses. Logistic regression was used for modelling presence-absence data (Hosmer and Lemeshow 2000). We ran the logistic regression analysis backwards by including all principal components and their 2-way interactions in the model first. At each step an non-significant interaction term or a main effect was removed, so that in the end all variables left in the model were significant. However, an non-significant main effect was retained if it was within a significant interaction term in the model. This procedure was continued until the most parsimonious model was obtained, using Akaike's information criterion (AIC; Burnham and Anderson 2003). AIC is a function of the model deviance and the number of variables in the model; the smaller the AIC value, the better the model.

We evaluated the accuracy of the probabilities for predictions using several statistics recommended by Fielding and Bell (1997). We estimated the accuracy of classifications by calculating rates of false positive and false negatives cases, and a Kappa $\mathrm{K}$ value. The Kappa $\mathrm{K}$ value estimates the model's overall agreement between predictions and actual data by comparing if the model predicts an occurrence better than a chance. Kappa $\mathrm{K}$ values range between 0.0 (random) and 1.0 (all cases correct), values $<0.4$ reflecting poor, $0.4-$ 0.75 good and $>0.75$ excellent fit with the data (Fielding and Bell 1997).

A cut-off point that separates model probabilities into presence and absence may affect the interpretation of the results. We used a threshold-independent receiving operating characteristic (ROC) plot (Fielding and Bell 1997) to measure the model's discrimination ability by plotting all sensitivity values (true positive fraction) against their equivalent (1-specificity) values (false positive fraction). The area under the ROC function, AUC, provides a single measurement for the overall accuracy that is not dependent on a particular cut-off threshold. The AUC value for the model ranges between 0.5 (no discrimination ability) and 1.0 (perfect discrimination).

We also evaluated the generality of the patterns found with our model. We split the data $(n=136)$ randomly into five parts of equal sizes. We selected four parts for a data subset, and repeated this procedure to get all five combinations of the subsets $(80 \%$ of the whole data in each subset). To build each sub-model, we ran principal component analysis with varimax rotation for the subset, interpreted the new principal components and, using the new components, ran logistic regression backwards using AIC in the model selection as before. This produced five sub-models. Statistical tests were done with SPSS (12.0.1.).

\section{Results}

In our study area, potential habitat covered $17.6 \%$ (6593 ha) of the total area, potential dispersal area 30\% (11231 ha), and areas incapable of being inhabited 52.4\% (18 476 ha), respectively. Forty-eight of the 136 habitat patches were occupied. We found no sings of flying squirrel presence from habitat patches that were situated above $300 \mathrm{~m}$ a.s.l. (except one habitat patch with a minimum elevation of $301 \mathrm{~m}$ ) (Fig. 2). About $44 \%$ of the area of habitat patches was situated above $300 \mathrm{~m}$ a.s.l.; habitat patch area below $300 \mathrm{~m}$ a.s.l. (3696 ha) covered $9.8 \%$ of the whole study area.

Occupied patches were larger in size, as well as the amount and proportion of core pixels, and tree volumes of spruce and deciduous trees per ha were greater than in unoccupied ones (Table 1). The landscape structure around habitat patches did not show large differences, even though unoccupied patches tended to have more potential dispersal area in their surroundings than occupied patches. Straight edge-to-edge distances from occupied patches to the nearest neighbour patches (SDnnp), and especially to the nearest occupied patches (SDnop), were shorter than from unoccupied patches. This result (Fig. 1) suggests that the patch configuration is spatially clustered to some extent in the landscape, but the occupied patches are even more clustered. The average least-cost distance to a nearest neighbour patch (CDnnp) did not differ much from occupied or from unoccupied patches, but least-cost distances between occupied patches (CDnop) were shorter than from unoccupied to occupied patches. On average, the least-

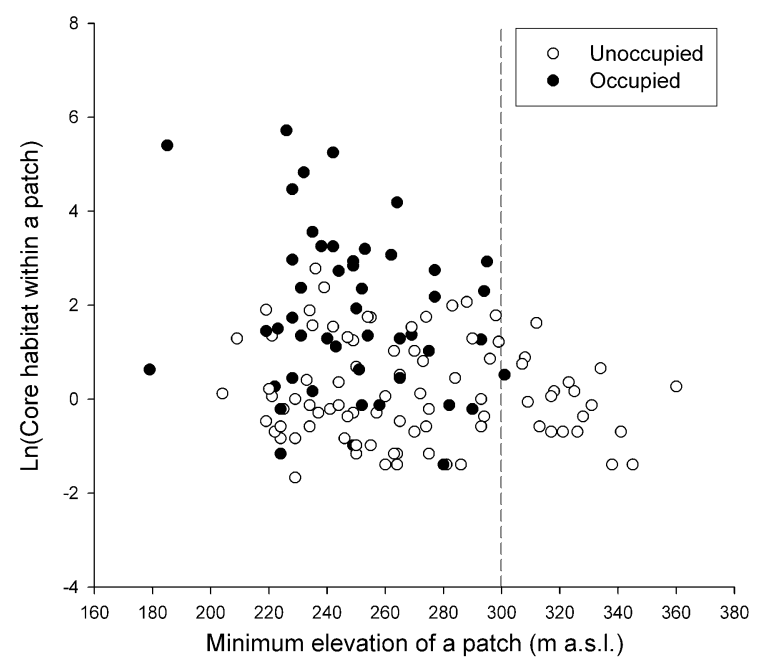

Fig. 2. The relationship between minimum elevation of a habitat patch and proportion of core habitat in a patch (lntransformed). No occupied patches were observed at higher elevation levels. 
Table 1. Comparison between occupied and unoccupied habitat patches using average (standard deviation in parenthesis). $\mathrm{n}=136$, with occupancy prevalence $35.3 \%$.

\begin{tabular}{|c|c|c|c|}
\hline \multicolumn{2}{|c|}{ Variable } & \multirow{2}{*}{$\begin{array}{c}\text { Presence (SD) } \\
134.9(276.5)\end{array}$} & \multirow{2}{*}{$\begin{array}{c}\text { Absence (SD) } \\
15.6(15.2)\end{array}$} \\
\hline 1 & Patch area (ha) & & \\
\hline 2 & Core-area (ha) & $28.0(61.2)$ & $2.1(2.6)$ \\
\hline 3 & Core-prop (\%) & $16.1(5.5)$ & $11.7(4.0)$ \\
\hline 4 & Core-group (number) & $74.4(147.1)$ & $9.5(9.4)$ \\
\hline 5 & Aslmin (m) & $248.6(26.4)$ & $269.9(37.1)$ \\
\hline 6 & Lowarea (ha) & $78.4(147.3)$ & $9.8(14.0)$ \\
\hline 7 & Spruce $\left(\mathrm{m}^{3} \mathrm{ha}^{-1}\right)$ & $51.4(11.9)$ & $43.5(10.5)$ \\
\hline 8 & Deciduous $\left(\mathrm{m}^{3} \mathrm{ha}^{-1}\right)$ & $12.7(3.2)$ & $10.6(2.8)$ \\
\hline 9 & PH500 (\%) & $11.4(7.9)$ & $10.2(10.2)$ \\
\hline 10 & DA500 (\%) & $31.4(13.6)$ & $38.5(14.8)$ \\
\hline 11 & IA500 (\%) & $57.2(13.3)$ & $51.3(18.2)$ \\
\hline 12 & SDnnp (m) & $191.1(409.7)$ & $232.3(255.4)$ \\
\hline 13 & SDnop (m) & $395.2(650.4)$ & $690.6(720.4)$ \\
\hline 14 & CDnnp (m) & $352.4(712.5)$ & $335.2(356.7)$ \\
\hline 15 & CDnop (m) & $741.6(1123.5)$ & $1141.2(1165.9)$ \\
\hline
\end{tabular}

cost distances were almost two times longer than straight edge-to-edge distances.

\section{Principal component analysis}

Five principal components (PC) with eigenvalues $>1$ explained almost $86 \%$ of the variation in the data (Table 2). About $27 \%$ of the variation was explained by PC1, which had high positive loadings for patch size variables, and we interpret $\mathrm{PC} 1$ to describe the size of a habitat patch. PC2 explained 19\% of the variation, with high positive loadings for distances to nearest occupied patches and a negative loading for the surrounding potential habitat. PC2 scales habitat patches using patch neighbourhood information so that habitat patches characteraised by a high amount of potential habitat in their surroundings and short distances to the nearest occupied patches are situated on the negative end of the PC2 axis. PC3 explained $16 \%$ of the variation, and yielded high loadings for the proportion of core pixels in a habitat patch as well as for the volumes of spruce and deciduous tree and, thus, indicates habitat patch quality. High positive loadings for potential dispersal area and high negative loadings for areas incapable of being inhabited in PC4 indicate that this axis correlates positively with structural connectivity in the surrounding landscape. PC5 had a high negative loading for minimum altitude of a habitat patch and positive loadings for distances to nearest neighbour patches. Habitat patches on the negative end of the PC5 axis are characterized by high altitude and short distances to the nearest neighbour patches, and describe high-elevation forests. PC4 explained ca 13\% and PC5 12\% of the variation.

\section{Model for the species occurrence in a habitat patch}

The simplest logistic regression model explained 87.5\% of the observed species occupancy pattern (Table 3). The model included all main effects (PC1-PC5) and interaction terms between $\mathrm{PC} 1$ and $\mathrm{PC} 5, \mathrm{PC} 2$, and PC4 and between PC2 and PC5 (Table 3). Absence of the flying squirrel was better predicted than presence (93.2\% and $77.1 \%$, respectively). The false negative rate was $22.9 \%$ (11 cases predicted unoccupied but

Table 2. Principal component with varimax-rotation $(n=136)$. High loadings representing the interpretation of each factor are shown in bold. PC1 refers to "patch size", PC2 to "neighbourhood", PC3 to "patch quality", PC4 to "structural connectivity", and PC5 to "high-elevation forests".

\begin{tabular}{|c|c|c|c|c|c|}
\hline & PC1 & PC2 & PC3 & PC4 & PC5 \\
\hline Patch area & 0.979 & -0.023 & 0.179 & 0.021 & 0.014 \\
\hline Core-area & 0.975 & -0.022 & 0.183 & 0.021 & 0.013 \\
\hline Core-prop & 0.273 & -0.039 & 0.859 & -0.095 & 0.095 \\
\hline Core-group & 0.980 & -0.027 & 0.176 & 0.018 & 0.013 \\
\hline Aslmin & -0.249 & 0.205 & 0.080 & 0.201 & -0.726 \\
\hline Lowarea & 0.955 & -0.054 & 0.190 & -0.016 & 0.074 \\
\hline Spruce & 0.208 & -0.076 & 0.862 & 0.151 & -0.092 \\
\hline Deciduous & 0.143 & -0.122 & 0.801 & -0.119 & -0.103 \\
\hline PH500 & -0.046 & -0.594 & -0.060 & 0.183 & -0.339 \\
\hline DA500 & 0.036 & 0.123 & -0.015 & 0.951 & -0.002 \\
\hline IA500 & -0.006 & 0.225 & 0.047 & -0.938 & 0.192 \\
\hline SDnnp & -0.116 & 0.578 & -0.206 & 0.042 & 0.703 \\
\hline SDnop & -0.047 & 0.944 & -0.119 & 0.049 & -0.056 \\
\hline CDnnp & -0.115 & 0.539 & -0.174 & -0.027 & 0.717 \\
\hline CDnop & -0.043 & 0.917 & -0.106 & 0.001 & 0.009 \\
\hline Eigenalue & 4.015 & 2.844 & 2.366 & 1.911 & 1.724 \\
\hline$\%$ of variance & 26.769 & 18.959 & 15.771 & 12.738 & 11.494 \\
\hline Cumulative\% & 26.769 & 45.728 & 61.499 & 74.237 & 85.731 \\
\hline
\end{tabular}


Table 3. Result of the logistic regression model $(n=136$, DF $=$ 9). With these principal components and interactions, a total of $87.5 \%$ of the occupancy status (absence $93.2 \%$, presence $77.1 \%$ ) was predicted correctly in the analysis.

\begin{tabular}{lrrrc}
\hline Principal component & \multicolumn{1}{c}{$\mathrm{B}$} & $\mathrm{SE}$ & Wald & $\mathrm{p}$ \\
\hline PC1 & 6.383 & 1.943 & 10.794 & 0.001 \\
PC2 & -0.966 & 0.359 & 7.241 & 0.007 \\
PC3 & 1.666 & 0.375 & 19.751 & 0.000 \\
PC4 & -0.408 & 0.303 & 1.812 & 0.178 \\
PC5 & -1.023 & 0.631 & 2.354 & 0.105 \\
PC1 $\times$ PC5 & -4.474 & 2.352 & 6.619 & 0.057 \\
PC2 $\times$ PC4 & 1.603 & 0.459 & 12.212 & 0.000 \\
PC2 $\times$ PC5 & 0.881 & 0.424 & 4.329 & 0.037 \\
Intercept & -0.004 & 0.444 & 0.000 & 0.993 \\
\hline
\end{tabular}

observed occupied), and false positive rate $6.8 \%$ (6 cases predicted occupied but observed unoccupied) (Fielding and Bell 1997). A Kappa $K$ value of 0.720 indicated a good fit with the data (Fielding and Bell 1997). In addition, the area under the ROC curve (AUC value 0.909) indicated good accuracy of the model with the data without regard to the threshold: for any randomly selected habitat patch the model would give a correct prediction $90 \%$ of the time.

A habitat patch was more probably occupied when it was larger in size (PC1) and of better quality (PC3), and when it had shorter distances to the nearest occupied patches (PC2). The interaction term "PC $1 \times$ PC5" reflects a relationship between the habitat patch size and the topography of the study area: smaller habitat patches (negative end of PC1) are often situated at higher elevations and are closer to other habitat patches (negative end of PC5). The interaction term "PC $2 \times$ PC4" suggests that the occupancy status of habitat patches is related to the landscape structure at the patch scale (Fig. 3). In the surroundings of an occupied habitat patch there often is more areas incapable of being inhabited than potential dispersal area (negative end of PC4), but the nearest neighbour distances to the occupied patches are relatively short (negative end of PC2). The areas incapable of being inhabited in the close surroundings of occupied patches mostly consisted of clear cuts and saplings (height $<4-$ $5 \mathrm{~m}$ ) since recent forestry practises have mainly decreased the size of the existing mature forest stands, but there were also open bogs, young forests (height $<8 \mathrm{~m}$ ), and a few small lakes or fields within the close surroundings. When there is a large amount of potential dispersal area in the habitat patch surroundings (positive end of PC4) the effect of distance to the nearest occupied patch on patch occupancy seem to be smaller (Fig. 3). The interaction term "PC2 $\times$ PC5" reflects the hilly topography of the study area. When habitat patches are situated at higher elevations (negative end of PC5) there is a more pronounced reduction in patch occupancy with increasing distance

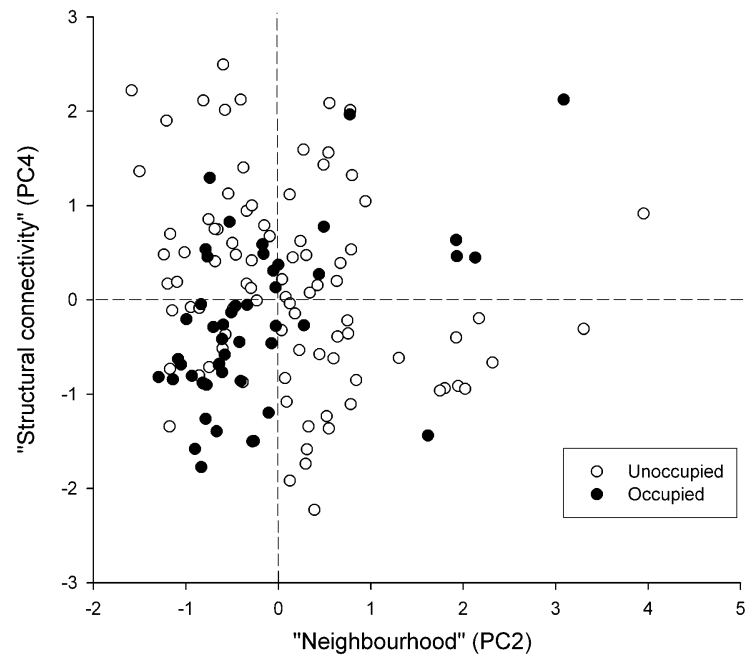

Fig. 3. The relationship between principal components PC2, "neighbourhood", and PC4, "structural connectivity". Habitat patches at the negative ends of both PC2 and PC4 have a shorter nearest neighbour distance between patches and more areas incapable of being inhabited in their surrounding than habitat patches at the positive ends have.

to neighbouring occupied patches than in habitat patches situated at low altitudes. Therefore, the effective distance between habitat patches also depends on elevation. This partially explains why habitat patches situated above $300 \mathrm{~m}$ a.s.l. were not found to be occupied.

Our modelling results with the whole data (Table 3) and with five sub-models (Appendix 1) were surprisingly robust. The variable loadings of principal components in the five sub-models could be interpreted similarly as with the full data (Appendix 1, Table 2). The "patch size" (PC1) and "patch quality" (PC3), and the interaction term between "neighbourhood" and "structural connectivity" in the surroundings (PC2 and PC4) were included in every sub-model. As such, this suggested their importance as rather general aspects for the occurrence of the Siberian flying squirrel in this landscape. Our modelling results were thus rather general, the differences relating mainly to "high-elevation forests" (PC5) and interactions, as well as to the model accuracy (i.e. values of Kappa K and AUC). Therefore, it seemed appropriate to examine general patterns explaining the phenomenon in question, while simultaneously showing the variability in different sub-models (such as the interactions in our study). If relying on only one model, the interpretation of the phenomenon may be limited.

Figure 3 illustrates a trend between the surrounding areas incapable of being inhabited and inter-patch distances, and that a majority of the occupied patches seemed to have negative values for both PC2 and PC4. 
We were interested in examining this relationship for possible "threshold limits", and focused only on the habitat patches for which PC4 scores $\leq 0$. These habitat patches were roughly surrounded by $>60 \%$ areas incapable of being inhabited $(74$ patches of which 32 were occupied). When patch surroundings were dominated by areas incapable of being inhabited, a straight edge-to-edge distance between two occupied patches (SDnop) was $136 \mathrm{~m}$ on average (95\% confidence interval $70-203 \mathrm{~m}$ ), whereas the average value for distances from an unoccupied patch to the nearest occupied patch was $896 \mathrm{~m}$ (95\% CI 651-1141 m; Mann-Whitney $U=1570, p=0.001)$. Similar responses were found for distances to any of the nearest neighbour patch (SDnnp: from an occupied patch the average was $108 \mathrm{~m}(95 \%$ CI $51-165 \mathrm{~m})$ and from an unoccupied patch $291 \mathrm{~m}$ (95\% CI 205-376 m); Mann-Whitney $\mathrm{U}=304.5, \mathrm{p}=0.0001$ ).

In our data, the habitat patch size distribution was biased towards smaller and mid-sized patches. We removed habitat patches $>100$ ha from the data (total of 11 patches from $100-200$ ha to the two largest being 1002 and 1430 ha in size), and repeated all analyses. Results were similar. Even though large habitat patches increased the amount of potential habitat and habitat patch sizes, the skewed distribution in the data did not appear to bias the landscape effects found in the modeling results.

\section{Discussion}

Our results showed many important patterns regarding the occurrence of the Siberian flying squirrel in our study area, which are valuable to landscape management. Consistent with earlier findings (Reunanen et al. 2002b, Selonen and Hanski 2004), occupied patches were larger in size and of better quality as they contained higher volumes of deciduous trees than unoccupied patches. Unoccupied patches at higher elevations are probably of lower quality because they often are characterised by thinner forests with smaller trees. Very interesting new findings were related to distances between habitat patches. Occupied patches had shorter distances, particularly to other occupied patches, measured via by both edge-to-edge and leastcost distances. In general, straight edge-to-edge distances were two to three times shorter than least-cost distances. However, the proportion of potential dispersal area within the $500 \mathrm{~m}$ radius around a habitat patch did not differ between the patch occupancy classes (Table 1 and PC4 in Table 3).

The patches of potential habitat (i.e. mature sprucedominated forests) within the landscape seemed to be aggregated in general (Fig. 1.), which is a function of both the underlying topography of the landscape and of forest harvesting (clustering of clear cuts in space and time). Distribution of individuals is rarely random in nature (Taylor et al. 1978), and in our study the occupied patches in the landscape were spatially clustered. This observed pattern does not indicate limited moving abilities of flying squirrels, since most of the edge-to-edge distances to the nearest neighbour patch were within $500 \mathrm{~m}$ in our study landscape, and the least-cost distances fell within the observed dispersal distances of flying squirrels (Selonen and Hanski 2004). Selonen and Hanski (2004) also reported that besides the small gaps within the gliding distances up to $70 \mathrm{~m}$, flying squirrels may cross open fields of $110-130 \mathrm{~m}$, and one individual was documented to have traversed a $300 \mathrm{~m}$ wide open field. Our finding may be related to preferences of the individuals as well as to population dynamics in time: the population processes are likely to be more stable if habitat patches are situated close to each other in clusters (McKelvey et al. 1993, Harrison and Fahrig 1995, Letcher et al. 1998). Unfortunately, with limited data we cannot recognise the underlying processes for the observed occupancy pattern.

Patch size and quality, as well as distances to the nearest patches, were the most important variables in our predictive model that explained $88 \%$ of the occupancy pattern of the species and seemed to be rather robust when compared with the sub-models. However, patch occupancy was not just a function of these characteristics but also depended on overall landscape structure. The significance of short interpatch distances was particularly pronounced when patch surroundings contained more areas incapable of being inhabited than potential dispersal area. The significant interaction term between "neighbourhood" (PC2) and "structural connectivity" (PC4) in the model suggests that the role of distances among habitat patches varies according to landscape composition (Fig. 3). Even though occupied patches had more potential habitat within their surroundings and the amount of areas incapable of being inhabited did not seem to matter within relatively short distances between habitat patches, occupancy of more distant habitat patches may be dependent on the forested connections.

A fruitful practical approach may be to consider landscape composition and configuration in light of the habitat patch network. The network consists of nodes and linkages that are surrounded by a landscape matrix, often the dominant element in the landscape (Forman 1995). We distinguished three landscape classes from the perspective of the flying squirrel. Areas incapable of being inhabited covered $52 \%$ of the landscape and represent the landscape matrix. The linkages (i.e. potential dispersal area) covered $30 \%$ of the study landscape. Therefore, at least $48 \%$ of the landscape (i.e. linkages together with the potential habitat, $17.6 \%$ ), can be used by flying squirrels to some extent. 
Therefore, even though potential habitat in our study landscape was broken up into separate patches (Fahrig 2003), the majority of the landscape seems to be functionally connected from the species' perspective. It is still difficult to identify the true functional aspects of a landscape, since actual movements of individuals between habitat patches or connectivity may be complicated to measure (Merriam 1995).

There also may be a threshold for habitat loss after which patch occupancy and species abundance is no longer a linear function of habitat availability (Andrén 1994). In our study area the proportion of potential habitat below $300 \mathrm{~m}$ a.s.l. was only $9.8 \%$. This is below the suggested $10-30 \%$ threshold level after which fragmentation effects may exacerbate the negative effects of habitat loss on population distribution and persistence based on empirical (Rolstad and Wegge 1987, Andrén 1994, Reunanen et al. 2004) and theoretical (Bascompte and Solé 1996, With et al. 1997, Fahrig 1998, Flather and Bevers 2002) studies. Furthermore, if we only consider the sites of preferred pixels within the habitat patches, the variable "corearea" covers on average $13 \%$ of the total habitat patch area. This suggests that important sites for feeding and cavity trees within spruce-dominated forests seem to be small in size, and relatively scarce in our study landscape.

Landscape configuration and connectivity are important, yet complicated spatial issues (Dunning et al. 1992, Merriam 1995). Earlier theoretical and empirical findings were mainly based on categorization of landscapes as either habitat patches or as matrix. Wiegand et al. (2005) used three landscape categories in their simulation studies and found that species persistence and population processes in the landscape may be enhanced by increasing the amount of dispersal habitat. The importance of matrix quality for the flying squirrel has also been found in Finland (Reunanen et al. 2000, 2002b, 2004, Selonen et al. 2001, Selonen and Hanski 2004). Habitat classification of the landscape forms the basis of our study. In ecological studies, it is crucial that the accuracy of the GIS data and the resulting habitat map from classification of satellite images has been checked properly (Holmgren and Thuresson 1998). Raster artefacts, systematic errors in habitat classification, and outdated habitat maps may have a negative impact on the quality of the data used in ecological study and further have a profound effect on the results. In our approach, misclassifications of satellite images were mostly systematic and related to middle-aged pine forests and vegetation patterns on shore lines (Kalliola and Syrjänen 1991).

We draw two general conclusion from our results. First, realistic definitions of suitable habitats for the flying squirrel must be incorporated into forestry planning procedures, since in the region where our study area is situated, forest harvesting by clear cutting is practised only in forest stands below $300 \mathrm{~m}$ a.s.l. Therefore, conflict between management for commercial forestry and for flying squirrel habitat persistence is further intensified if the amount of suitable habitat in the lowlands is decreased on the assumption that ample suitable habitat remains at higher elevations. Second, occurrence of flying squirrels seemed to be more probable with short distances between habitat patches or forested connections between habitat patches. On the scale of our study areas incapable of being inhabited surrounding the habitat patches does not seem to be a problem, since within the habitat patch clusters, totally open areas can also be traversed. Flying squirrels are relatively mobile, but if habitat patches are very distant, least-cost distances may provide a more practical measure for probable connections between patches. This emphasises the consideration of the forests suitable for dispersal between distant habitat patches.

In conclusion, the future challenge of ecological research is to connect landscape patterns to population processes (Kareiva and Wennergren 1995, Hanski 1999). The breeding sites of the flying squirrel (e.g. core areas and cavity trees) and some moving connections to the nearby forests are already maintained in forestry practises in Finland (Anon. 2003), but a broader spatiotemporal approach is still needed. While increasing our knowledge by research, maintaining a clustered arrangement of good quality habitat patches and regenerating new potential habitat as well as dispersal areas between habitat patches seem to be appropriate goals for long-term forest management to enhance persistence of the flying squirrel in the landscape. The network idea, with nodes and linkages (Forman 1995), in landscape planning may well be one approach to maintain the Siberian flying squirrel in boreal forest landscape in northern Finland.

Acknowledgements - We are grateful to the staff of NFI for making these data available. We warmly thank R. Gasol Escuer for her help in the field, Mrs Yli-Sirniö for pleasant coffee breaks, and A. Bergdahl for editing the language. The useful comments from the subject editor improved the paper markedly. This study was financed by the Intrinsic Centre of Excellence funding by the Univ. of Oulu, the Finnish Forest Industries Federation, the Maj and Tor Nessling Foundation, and the Ministry of Agriculture and Forestry of Finland.

\section{References}

Åberg, J. et al. 1995. The effect of matrix on the occurrence of hazel grouse (Bonasa bonasia) in isolated habitat fragments. - Oecologia 103: 265-269.

Ahti, T. et al. 1968. Vegetation zones and their sections in northwestern Europe. - Ann. Bot. Fenn. 5: 169-211. 
Andrén, H. 1994. Effects of habitat fragmentation on birds and mammals in landscape with different proportion of suitable habitat: a review. - Oikos 71: 340-346.

Anon. 2003. Liito-oravan lisääntymis- ja levädyspaikkojen määrittäminen ja turvaaminen metsien käytössä (MMM Dnro 3713/430/2003, YM 4/501/3002). (A guideline for determining and maintaining breeding and resting sites of the flying squirrel in the forest use.) - Ministry of Agriculture and Forestry, and Ministry of the Environment, in Finnish.

Bascompte, J. and Solé, R.V. 1996. Habitat fragmentation and extinction thresholds in spatially explicit models. - J. Anim. Ecol. 65: 465-473.

Bender, D. J. et al. 1998. Habitat loss and population decline: a meta-analysis of the patch size effect. - Ecology 79: 517-533.

Burnham, K. P. and Anderson, D. R. 2003. Model selection and inference: a practical information-theoretic approach. - Springer.

Dunning, J. B. et al. 1992. Ecological processes that affect populations in complex landscapes. - Oikos 65: 169175.

Esseen, P.-A. et al. 1997. Boreal forests. - Ecol. Bull. 46: 1647.

Fahrig, L. 1997. Relative effects of habitat loss and fragmentation on population extinction. - J. Wildl. Manage. 61: 603-610.

Fahrig, L. 1998. When does fragmentation of breeding habitat affect population survival? - Ecol. Modell. 105: $273-292$.

Fahrig, L. 2002. Effect of habitat fragmentation of the extinction threshold: a synthesis. - Ecol. Appl. 12: $346-353$.

Fahrig, L. 2003. Effects of habitat fragmentation on biodiversity. - Annu. Rev. Ecol. Evol. Syst. 34: 487-515.

Fielding, A. H. and Bell, J. F. 1997. A review of methods for assessment of prediction errors in conservation presence/ absence models. - Environ. Conserv. 24: 38-49.

Flather, C. H. and Bevers, M. 2002. Patchy reaction-diffusion and population abundance: the relative importance of habitat amount and arrangement. - Am. Nat. 159: 4056.

Forman, R. T. T. 1995. Land mosaics - the ecology of landscapes and regions. - Cambridge Univ. Press.

Gustavsen, H. G. 1980. Talousmetsien kasvupaikkaluokittelu valtapituuden avulla. (Site index curves for conifer stands in Finland.) - Folia Forestalia 454: 1-31, in Finnish with English summary.

Hanski, I. 1999. Metapopulation ecology. - Oxford Univ. Press.

Hanski, I. K. 1998. Home range and habitat use in the declining flying squirrel Pteromys volans in managed forests. - Wildl. Biol. 4: 33-46.

Hanski, I. K. et al. 2000. Home range size, movements, and nest-site use in the Siberian flying squirrel (Pteromys volans). - J. Mammal. 81: 798-809.

Harrison, S. and Fahrig, L. 1995. Landscape pattern and population conservation. - In: Hansson, L. et al. (eds), Mosaic landscapes and ecological processes. IALE Studies in Landscape Ecology. Vol. 2. Chapman and Hall, pp. $293-308$.
Harrison, S. and Bruna, E. 1999. Habitat fragmentation and large-scale conservation: what do we know for sure? - Ecography 22: 225-232.

Holmgren, P. and Thuresson, T. 1998. Satellite remote sensing for forestry planning - a review. - Scand. J. For. Res. 13: 90-110.

Hosmer, D. W. and Lemeshow, S. 2000. Applied logistic regression, 2nd ed. - Wiley.

Kalliola, R. and Syrjänen, K. 1991. To what extent are vegetation types visible in satellite imagery? - Ann. Bot. Fenn. 28: 45-57.

Kareiva, P. and Wennergren, U. 1995. Connecting landscape patterns to ecosystem and population processes. - Nature 373: 299-302.

Letcher, B. H. et al. 1998. An individual-based, spatiallyexplicit simulation model of the population dynamics of the endangered red-cockaded woodpecker, Picoides borealis. - Biol. Conserv. 86: 1-14.

Lidicker, W. Z. Jr 1999. Responses of mammals to habitat edges: an overview. - Landscape Ecol. 14: 333-343.

Mac Nally, R. 2000. Regression and model-building in conservation biology, biogeography and ecology: the distinction between - and reconciliation of - 'predictive' and 'explanatory' models. - Biodiv. Conserv. 9: 655671.

McCoy, J. and Johnston, K. 2001. Using ArcGIS ${ }^{\mathrm{TM}}$ spatial analyst. - ESRI, USA.

McKelvey, K. et al. 1993. Conservation planning for species occupying fragmented landscapes: the case of the northern spotted owl. - In: Kareiva, P. M. et al (eds), Biotic interactions and global change. Sinauer, pp. 424-450.

Merriam, G. 1984. Connectivity: a fundamental ecological characteristics of landscape pattern. - In: Brandt, J. and Agger, P. (eds), Methodology in landscape ecological research and planning. Roskilde Universitetsforlag, GeuRuc, Roskilde, Denmark, pp. 5-15.

Merriam, G. 1995. Movement in spatially divided populations: responses to landscape structure. - In: Lidicker, W. Z. Jr (ed.), Landscape approaches in mammalian ecology and conservation. Univ. of Minnesota Press, pp. 64-77.

Mönkkönen, M. et al. 1997. Landscape characteristics associated with the occurrence of the flying squirrel Pteromys volans in old-growth forests of northern Finland. - Ecography 20: 634-642.

Nikula, A. et al. 2001. Evaluating the impact of forest management on landscape functioning: dispersal network models for flying squirrel as an example. - In: Vuori, K.M. and Kouki, J. (eds), Ecosystem management in boreal forest landscape. International Conference in Koli National Park, Finland, May 27-30, 2001, p. 82.

Östlund, L. et al. 1997. The history and transformation of a Scandinavian boreal forest landscape since the 19th century. - Can. J. For. Res. 27: 1198-1206.

Rassi, P. et al. (eds) 2001. Suomen lajien uhanalaisuus 2000. - Ympäristöministeriö and Suomen ympäristökeskus, Helsinki, in Finnish with English summary.

Ray, N. et al. 2002. Modeling spatial distribution of amphibian populations: a GIS approach based on habitat matrix permeability. - Biodiv. Conserv. 11: 2143-2165.

Reunanen, P. et al. 2000. Managing boreal forest landscapes for the flying squirrel. - Conserv. Biol. 14: 218-226. 
Reunanen, P. et al. 2002a. Habitat requirements of the Siberian flying squirrel in northern Finland: comparing field survey and remote sensing data. - Ann. Zool. Fenn. 39: $7-20$.

Reunanen, P. et al. 2002b. Predicting occupancy for the Siberian flying squirrel in old-growth forests. - Ecol. Appl. 12: 1188-1198.

Reunanen, P. et al. 2004. Assessing landscape thresholds for the Siberian flying squirrel. - Ecol. Bull. 51: 277-286.

Rolstad, J. and Wegge, P. 1987. Distribution and size of capercaillie leks in relation to old forest fragmentation. - Oecologia 72: 389-394.

Saunders, D. A. et al. 1991. Biological consequences of ecosystem fragmentation: a review. - Conserv. Biol. 5: $18-32$.

Selonen, V. and Hanski, I. K. 2003. Movements of the flying squirrel Pteromys volans in corridors and in matrix habitat. - Ecography 26: 641-651.

Selonen, V. and Hanski, I. K. 2004. Young flying squirrels (Pteromys volans) dispersing in fragmended forests. - Behav. Ecol. 15: 564-571.

Selonen, V. et al. 2001. Space use of the Siberian flying squirrel Pteromys volans in fragmented forests. - Ecography 24: 588-600.

Download the appendix as file E4744 from

$<$ www.oikos.ekol.lu.se/appendix $>$.
Soulé, M. E. 1985. What is conservation biology? - BioScience 35: 727-734.

Taylor, L. R. et al. 1978. The density-dependence of spatial behaviour and the rarity of randomness. - J. Anim. Ecol. 47: 383-406.

Taylor, P. D. et al. 1993. Connectivity is a vital element of landscape structure. - Oikos 68: 571-572.

Tischendorf, L. and Fahrig, L. 2000. On the usage and measurement of landscape connectivity. - Oikos 90: 719.

Tomppo, E. 1993. Multi-source National Forest Inventory of Finland. - The Finnish Forest Research Inst. Research Papers 444: 52-59.

Tomppo, E. et al. 1998. Kunnittaiset metsävaratiedot 199094. - Folia Forestalia 4B/1998: 619-839.

Wiegand, T. et al. 2005. Effects of habitat loss and fragmentation on population dynamics. - Conserv. Biol. 19: 108-121.

Wiens, J. A. 1995. Landscape mosaics and ecological theory. - In: Hansson, L. et al. (eds), Mosaic landscape and ecological processes. Chapman and Hall, pp. 1-26.

With, K. et al. 1997. Landscape connectivity and population distribution in heterogeneous environments. - Oikos 78: $151-169$. 